\title{
Analisis Resiko Lingkungan pada Tempat Pembuangan Akhir (TPA) Sampah (Studi Kasus: TPA Piyungan Bantul)
}

\author{
Kasam \\ Program Studi Teknik Lingkungan FTSP Universitas Islam Indonesia Yogyakarta
}

\begin{abstract}
Abstrak
Pembuangan sampah perkotaan pada Tempat Pembuangan Akhir (TPA) adalah cara yang paling banyak diterapkan di beberapa kota di Indonesia termasuk di Kota Yogyakarta. Timbulan sampah di wilayah perkotaan Yogyakarta sampai saat ini dilakukan di TPA Piyungan Kabupaten Bantul. Meskipun hal ini merupakan metode yang paling konvesional dan tidak sesuai dengan beberapa alternative yang lebih baik dalam rangkaian teknologi manajemen sampah perkotaan. Dengan adanya TPA maka akan diikuti dampak negatif terhadap lingkungan. Dampak negatif tersebut adalah dihasilkan timbulan gas dan lindi yang sangat berpotensi merusak lingkungan. Risiko lingkungan ini muncul jika Instalasi Pengolahan Air Limbah (IPAL) tidak mampu mengolah lindi sehingga melebihi standard baku mutu serta lapisan dasar TPA yang tidak memenuhi syarat sehingga lindi merembes kedalam tanah.

Oleh karena itu dibutuhkan aplikasi sistematis dalam meminimasi kemungkinan terjadinya risiko terhadap lingkungan. Dalam studi ini dilakukan identifikasi dan analisis risiko lingkungan berdasarkan konsep manajemen risiko lingkungan dengan menggunakan metode kualitatif dan metode semi kuntitatif. Berdasarkan hasil identifikasi risiko dan analisis risiko terdapat empat komponen lingkungan yang mempunyai risiko tinggi yaitu pencemaran udara, pencemaran air tanah, berkurangnya estetika lingkungan dan pencemaran air permukaan yang disebabkan adanya timbulan gas, aliran lindi, rembesan lindi pada tanah serta bau.
\end{abstract}

Kata kunci: Sampah perkotaan, TPA, Resiko Lingkungan

\section{Pendahuluan}

Sampah merupakan konsekuensi dari adanya aktifitas manusia. Setiap aktifitas manusia pasti menghasilkan buangan atau sampah. Jumlah atau volume sampah sebanding dengan tingkat konsumsi manusia terhadap barang/material yang kita gunakan sehari-hari. Demikian juga dengan jenis sampah, sangat tergantung dari jenis material yang dikonsumsi. Oleh karena itu pegelolaan sampah tidak bisa lepas juga dari ‘pengelolaan’ gaya hidup masyarakat.

Peningkatan jumlah penduduk dan perubahan gaya hidup sangat berpengaruh pada volume sampah yang ditimbulkan. Di kota Jakarta pada tahun 1985 menghasilkan sampah sejumlah $18.500 \mathrm{~m}^{3}$ per hari dan pada tahun 2000 meningkat menjadi $25.700 \mathrm{~m}^{3}$ per hari. Jika dihitung dalam setahun, maka volume sampah tahun 2000 mencapai 170 kali besar Candi Borobudur (volume Candi Borobudur $=55.000 \mathrm{~m}^{3}$ ). [Bapedalda, 2000]. Selain Jakarta, jumlah sampah yang cukup besar terjadi di Medan dan Bandung. Kota metropolitan lebih banyak menghasilkan sampah dibandingkan dengan kota sedang atau kecil. Di Kota Jogjakarta menurut data DKKP pada tahun 2005 produksi sampah kawasan perkotaan sebanyak $1.700 \mathrm{~m}^{3}$ perhari, namun yang dapat diangkut ke TPA Pinyungan-Bantul baru sekitar $1300 \mathrm{~m}^{3}$ perhari, sehingga terjadi penumpukan sampah sebanyak $400 \mathrm{~m}^{3}$ per hari dan tidak terangkut ke TPS atau TPA Piyungan. Karena itu wajar kalau dibanyak 
lokasi, tanah-tanah kosong atau bantaran sungai di aglomerasi kota Jogjakarta terjadi penumpukanpenumpukan sampah yang kemudian berubah menjadi TPS atau TPA Illegal. Di TPA Baleharjo, Wonosari, sudah mengkhawatirkan bakal mencemari lingkungan. Akibat tumpukan sampah yang menggunung banyak menimbulkan lalat di sekitar lokasi dan bau yang tidak sedap. Meskipun jarak lokasi dengan pemukiman penduduk agak jauh, tetapi lalat sudah sampai di lokasi pemukiman (Kedaulatan Rakyat, 17/02/2009).

TPA Piyungan terletak di Kabupaten Bantul, $\pm 16 \mathrm{~km}$ sebelah tenggara pusat Kota Yogyakarta, dengan luas lahan 12 Ha. TPA ini terletak di RT 04 Dukuh Bendo Ngablak dan RT 05 Dukuh Watu Gender, Desa Sitimulyo, Kecamatan Piyungan, Kabupaten Bantul, Daerah Istimewa Yogyakarta.

Metode pengolahan sampah di TPA Piyungan adalah menggunakan sistem “Sanitary Landfill”, tumpukan sampah dilapisi dengan timbunan tanah, serta terdapat kolam pengolahan "leachate (lindi)” pipa pengendali gas buang, sistem drainase dan lapisan kedap air. Cakupan layanan TPA Piyungan adalah daerah perkotaan Yogyakarta yang meliputi Kota Yogyakarta, Kabupaten Sleman bagian selatan dan Kabupaten Bantul bagian utara yang masuk wilayah perkotaan

Sangat mungkin bahwa leachate yang dihasilkan dari degradasi sampah akan bergerak melalui poripori tanah yang selanjutnya akan bercampur dengan air tanah (groundwater). Dengan aliran groundwater yang terkontaminasi, maka meskipun dengan aliran yang lambat (meter per hari bahkan centimeter per tahun) pencemar akan terpapar ke lingkungan sekitar TPA (SEPA., 2002).

Dengan berbagai kondisi persampahan yang ada seperti tersebut di atas, sejak dioperasikan TPA Piyungan maka berbagai dampak negatif yang kemungkinan akan muncul dan berpotensi menimbulkan resiko, antara lain adalah:

- Perubahan tata guna lahan

- Pencemaran udara

- Pencemaran air tanah

- Pencemaran air permukaan

- Penurunan jumlah flora darat (terestrial)

- Penurunan jumlah flora air (aquatik)

- Penurunan jumlah fauna darat

- Penurunan jumlah fauna air

- Penurunan tingkat kesehatan masyarakat

- Berkurangnya estetika lingkungan

Dari beberapa dampak negatif yang kemungkinan akan terjadi, maka diperlukan suatu penilaian (assessment) terhadap resiko lingkungan. Dimana penilaian resiko tersebut bisa dinyatakan dalam nilai resiko kumulatif maupun secara parsial. Pada sebuah TPA, stressor yang kemungkinan 
memberikan nilai resiko yang cukup dominan adalah leachate dan timbulan gas Golder Associates (NZ) Ltd, (2002),. Hal ini disebabkan oleh sifat leachate yang mengandung zat-zat kimia berbahaya dan dapat menyebar pada beberapa komponen lingkungan seperti tanah, air tanah dan air permukaan. Sedangkan dimungkinkan air yang sudah tekontaminasi zat-zat kima leachate akan dikonsumsi oleh masyarakat ataupun penggunaan lainnya. Oleh karena itu dalam kegiatan studi ini akan dilakukan penilaian resiko total. Secara umum resiko total merupakan fungsi dari faktorfaktor: peluang terjadinya dampak, besaran dampak, frekuensi kejadian, luasan dampak, keseriusan resiko, peluang terjadinya resiko, dan waktu pemaparan.

\section{Metodologi}

Penilaian resiko lingkungan merupakan sebuah proses untuk pengumpulan, pengorganisasian, analisis untuk mengestimasi kemungkingan dan ketidakpastian dampak yang tidak diinginkan pada lingkungan (manusia, organisme, dan populasi lainnya). Penilaian resiko didasarkan pada pemahaman bahwa keputusan diambil dibawah kondisi ketidakpastian serta kemauan dari ketergantungan keluaran (output) serta mendapatkan kemungkinan manfaat sebaik-baiknya (Glenn W. Suter II, et al., 2000). Penilaian resiko lingkungan adalah sebuah dokumen yang secara garis besar berisi gabungan resiko kesehatan melalui paparan kontaminan lingkungan pada suatu tempat dan menentukan justifikasi untuk mengambil langkah remediasi atau pemindahan kontaminan (Susan Dempsey, MS, 2007). Pada dasarnya penilaian resiko mempunyai pendekatan struktur untuk menentukan secara alami dan pasti antara penyebab dan efek atau akibatnya. Secara garis besar, proses penilaian resiko mengikuti kerangka seperti ditunjukkan Gambar 1.

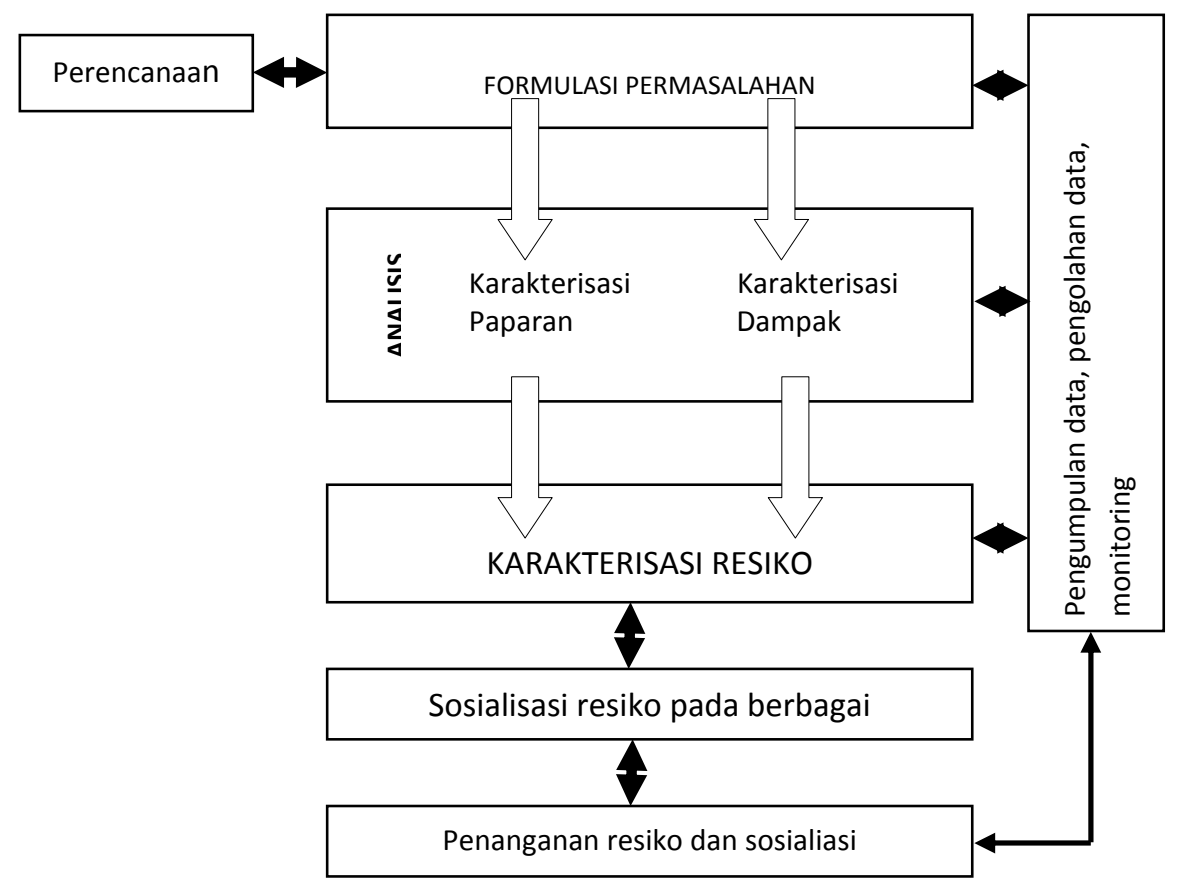

Gambar 1. Kerangka Penilaian Resiko Lingkungan (USEPA, 1998) 
Sedangkan Tahapan-tahapan penilaian resiko meliputi: Indentifikasi resiko, Analisis resiko, Penilaian resiko atau Estimasi resiko dan Evaluasi resiko. Berbagai metode analisis yang digunakan dalam penilaian resiko lingkungan antara lain adalah: metode kualitatif dan metode semi kuantitatif (Damayanti A. dkk., 2004).

a. Metode kualitatif

Analisis resiko dengan metode kualitatif dilakukan dengan mengkombinasikan antara nilai peluang terjadinya resiko (seperti Tabel 1) dan besarnya resiko (seperti pada Tabel 2) sehingga akan dihasilkan nilai resiko yang terdiri dari resiko tinggi, resiko menengah, resiko berarti, dan resiko rendah seperti ditunjukkan pada Tabel 3.

Tabel 1. Matriks Peluang Terjadinya Resiko

\begin{tabular}{|c|l|l|l|}
\hline Level & $\begin{array}{c}\text { Peluang terjadinya } \\
\text { resiko (kemungkinan) }\end{array}$ & Uraian \\
\hline A & Hampir pasti & $\begin{array}{l}\text { Kegiatan yang dilakukan diperkirakan hampir pasti menimbulkan } \\
\text { resiko terhadap lingkungan disekitarnya. Hal ini merupakan peringkat } \\
\text { tertinggi }\end{array}$ \\
\hline B & Kemungkinan besar & $\begin{array}{l}\text { Kegiatan yang dilakukan diperkirakan kemungkinan besar akan } \\
\text { menimbulkan resiko terhadap lingkungan disekitarnya. Hal ini } \\
\text { merupakan peringkat besar }\end{array}$ \\
\hline C & Kemungkinan sedang & $\begin{array}{l}\text { Kegiatan yang dilakukan diperkirakan kemungkinan sedang } \\
\text { menimbulkan resiko terhadap lingkungan disekitarnya. Hal ini } \\
\text { merupakan peringkat sedang }\end{array}$ \\
\hline D & Kemungkinan kecil & $\begin{array}{l}\text { Kegiatan yang dilakukan diperkirakan kemungkinan kecil } \\
\text { menimbulkan resiko terhadap lingkungan disekitarnya. Hal ini } \\
\text { merupakan peringkat kecil }\end{array}$ \\
\hline E & Jarang & $\begin{array}{l}\text { Kegiatan yang dilakukan diperkirakan tidak atau jarang menimbulkan } \\
\text { resiko terhadap lingkungan disekitarnya. Hal ini merupakan peringkat } \\
\text { kecil }\end{array}$ \\
\hline
\end{tabular}

Tabel 2. Matriks Besaran Resiko

\begin{tabular}{|c|l|l|l|}
\hline Level & $\begin{array}{l}\text { Hirarkhi Besaran resiko } \\
\text { (pengaruh/konsekuensi) }\end{array}$ & \multicolumn{1}{|c|}{ Uraian } \\
\hline 1 & Pengaruh tidak berarti & $\begin{array}{l}\text { Kegiatan yang dilakukan diperkirakan akan menimbulkan } \\
\text { pengaruh yang tidak berarti terhadap lingkungan disekitarnya. Hal } \\
\text { ini merupakan peringkat rendah }\end{array}$ \\
\hline 2 & Pengaruh kecil & $\begin{array}{l}\text { Kegiatan yang dilakukan diperkirakan akan menimbulkan } \\
\text { engaruh kecil terhadap lingkungan disekitarnya. Hal ini } \\
\text { merupakan peringkat kecil }\end{array}$ \\
\hline 3 & Pengaruh sedang & $\begin{array}{l}\text { Kegiatan yang dilakukan diperkirakan akan menimbulkan } \\
\text { pengaruh sedang terhadap lingkungan disekitarnya. Hal ini } \\
\text { merupakan peringkat sedang }\end{array}$ \\
\hline 4 & Pengaruh besar & $\begin{array}{l}\text { Kegiatan yang dilakukan diperkirakan akan menimbulkan } \\
\text { pengaruh besar terhadap lingkungan disekitarnya. Hal ini } \\
\text { merupakan peringkat kedua }\end{array}$ \\
\hline 5 & $\begin{array}{l}\text { Pengaruh sangat besar } \\
\text { (bencana) }\end{array}$ & $\begin{array}{l}\text { Kegiatan yang dilakukan diperkirakan akan menimbulkan } \\
\text { pengaruh yang sangat besar atau akan menimbulkan bencana } \\
\text { terhadap lingkungan disekitarnya. Hal ini merupakan peringkat } \\
\text { tertinggi }\end{array}$ \\
\hline
\end{tabular}


Tabel 3. Penilaian resiko secara kualitatif

\begin{tabular}{|l|l|l|l|l|l|l|}
\hline & \multicolumn{6}{l}{ Hirarkhi Besaran resiko (pengaruh/konsekuensi) } \\
\hline \multirow{4}{*}{$\begin{array}{l}\text { Peluang terjadinya resiko } \\
\text { (kemungkinan) }\end{array}$} & & 1 & 2 & 3 & 4 & 5 \\
\cline { 2 - 8 } & $\mathrm{A}$ & $\mathrm{M}$ & $\mathrm{M}$ & $\mathrm{H}$ & $\mathrm{H}$ & $\mathrm{H}$ \\
\cline { 2 - 8 } & $\mathrm{B}$ & $\mathrm{S}$ & $\mathrm{M}$ & $\mathrm{M}$ & $\mathrm{H}$ & $\mathrm{H}$ \\
\cline { 2 - 8 } & $\mathrm{C}$ & $\mathrm{L}$ & $\mathrm{S}$ & $\mathrm{M}$ & $\mathrm{H}$ & $\mathrm{H}$ \\
\cline { 2 - 8 } & $\mathrm{D}$ & $\mathrm{L}$ & $\mathrm{L}$ & $\mathrm{S}$ & $\mathrm{M}$ & $\mathrm{H}$ \\
\cline { 2 - 7 } & $\mathrm{E}$ & $\mathrm{L}$ & $\mathrm{L}$ & $\mathrm{S}$ & $\mathrm{M}$ & $\mathrm{M}$ \\
\hline
\end{tabular}

keterangan:

$\mathrm{H}$ : Resiko tinggi

$\mathrm{M}$ : Resiko menengah

$\mathrm{S}$ : Resiko berarti

L : Resiko rendah

b. Metode semi kuantitatif

Analisis resiko dengan menggunakan metode semi kuantitatif adalah menggabungkan antara unsur frekuensi kejadian, besaran kejadian dan sensitifitas seperti terlihat pada Tabel 4. Sedangkan nilai resiko seperti pada persamaan (1) (Razif. M., 2002).

Resiko $=$ Frekuensi kejadian $\mathrm{x}($ Besaran kejadian + Sensitifitas $)$

$\mathrm{R}=\mathrm{F} \times(\mathrm{S} 1+\mathrm{S} 2)$

Dimana jika,

$\mathrm{R}=1-150 \quad$ : Resiko rendah, pengelolaan dengan prosedur yang rutin

$\mathrm{R}=151-300 \quad$ : Resiko sedang, memerlukan perhatian manajemen tingkat tinggi

$\mathrm{R}=301-450 \quad$ : Resiko tinggi, memerlukan penelitian dan manajemen terperinci

Tabel 4. Frekuensi kejadian (F), Besaran kejadian (S1), dan Sensitifitas (S2)

\begin{tabular}{|c|l|l|l|}
\hline Level & \multicolumn{3}{|c|}{ Uraian } \\
\hline & Frekuensi kejadian (F) & Besaran kejadian (S1) & Sensitifitas (S2) \\
\hline 1 & $\begin{array}{l}\text { Ada kemungkinan tidak } \\
\text { terjadi }\end{array}$ & Resiko tidak ada & $\begin{array}{l}\text { Menjadi perhatian } \\
\text { internasional/dunia/media }\end{array}$ \\
\hline 2 & Kecil & Resiko dan pengaruhnya kecil & Menjadi perhatian nasional \\
\hline 3 & Medium & Resiko sedang & $\begin{array}{l}\text { Menjadi perhatian } \\
\text { regional/local }\end{array}$ \\
\hline 4 & Sering terjadi & Resiko besar & Menjadi perhatian kelompok \\
\hline 5 & Sangat sering terjadi & Resiko besar sekali & $\begin{array}{l}\text { Tidak menjadi perhatian } \\
\text { masyarakat }\end{array}$ \\
\hline
\end{tabular}

\section{Hasil dan Pembahasan}

Sebelum melakukan identifikasi resiko lingkungan akibat aktifitas TPA, perlu terlebih dahulu diketahui rona lingkungan wilayah studi, yang meliputi rona fisik kimia, biologi, serta sosial, ekonomi dan budaya masyarakat. Berdasarkan obeservasi dan data sekunder di ketahui bahwa rona 
lingkungan TPA Piyungan merupakan daerah pemukiman. Sebagian besar wilayah studi merupakan pemukiman yang memiliki beberapa kelompok hutan kota. Tumbuhan yang ada di disekitar TPA Piyungan adalah yang dapat hidup baik di dataran rendah yaitu: akasia, sono, trembesi, bungur, bambu, meranti, medang. Fauna yang umum ada di wilayah studi adalah fauna yang biasa diternakkan oleh warga seperti sapi, kambing, kerbau, domba, ayam, dan itik. Adapun kerangka system konstruksi TPA seperti dijelaskan pada Gambar 2.

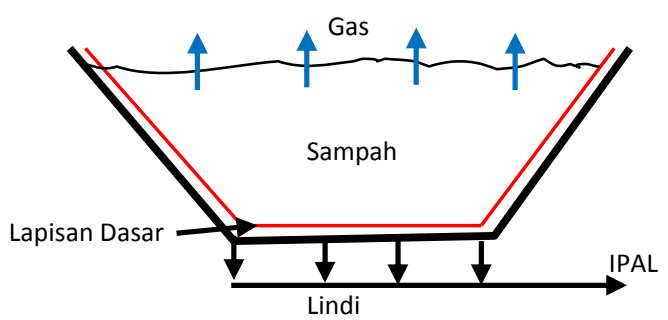

Gambar 2. Skema Konstruksi TPA (SEPA, 2002)

\section{Identifikasi Hazard dan Resiko}

Dari uraian rona lingkungan yang dijelaskan dan penjelasan tentang aktifitas TPA sebagaimana disebutkan di atas, dapat diidentifikasi hazard dan diperkirakan resiko terhadap komponen lingkungan sebagai berikut:

a. Tata guna lahan (tanah)

Prakiraan resiko terhadap tata guna lahan yang mungkin terjadi yaitu resiko berasal dari buangan limbah terutama lindi yang mencemari air tanah dan air permukaan. Akibat pencemaran tersebut maka warga merasa tidak nyaman dan pindah dari lokasi sekitar TPA Piyungan, sehingga terjadi perubahan tata guna lahan. Di samping itu diprakirakan masyarakat akan menjual tanahnya karena beranggapan lahannya tidak strategis.

b. Kualitas udara

Prakiraan resiko terhadap udara, yaitu resiko berasal dari bau gas yang timbul dari proses degradasi sampah yang semakin lama semakin tidak sedap. Akibat pencemaran tersebut warga khususnya masyarakat disekitar TPA Piyungan merasa kurang nyaman akibat terhisapnya bau ke dalam pernafasan. Jenis resiko yang muncul bersifat negatif. Bobotnya besar karena pencemaran gas yang timbul jumlahnya besar dan berlangsung terus menerus serta merupakan gas yang berbahaya.

c. Kualitas air permukaan

Prakiraan resiko terhadap air permukaan yaitu berasal dari pengolahan limbah cair, yang dibuang ke sungai. Resiko yang timbul pada flora, fauna, dan manusia, yang memanfaatkan 
sungai. Resiko terbesar yang mungkin terjadi adalah matinya biota air, tumbuhan air, dan hewan air. Resiko yang muncul bersifat negatif.

d. Kualitas air tanah

Prakiraan resiko terhadap air tanah yaitu berasal dari pengolahan lindi dan rembesan lindi pada lapisan dasar TPA. Resiko yang timbul pada manusia, yang memanfaatkan air tanah untuk keperluan sehari-hari.

e. Flora darat

Prakiraan resiko terhadap flora darat berasal dari pengolahan limbah cair kemudian kemudian dibuang ke sungai lalu dihisap oleh tumbuhan yang hidup di sekitar sungai. Selain itu gangguan terhadap flora air adanya gas Methan. Resiko yang mungkin timbul berupa berkurangnya kemampuan tumbuhan dalam berfotosintesis sehingga menyebabkan tumbuhan tersebut mati serta bersifat negatif. Tetapi bobotnya sedang karena effluen dari IPAL telah mengalami pengenceran air sungai sehingga konsentrasi pencemar juga menurun.

f. Flora air

Prakiraan resiko terhadap flora air berasal dari pengolahan limbah cair kemudian kemudian dibuang ke sungai lalu dihisap oleh tumbuhan yang hidup di sekitar sungai. Selain itu gangguan terhadap flora air juga dari adanya gas Methan. Resiko yang mungkin timbul berupa berkurangnya kemampuan tumbuhan dalam berfotosintesis sehingga menyebabkan tumbuhan tersebut mati serta bersifat negatif. Tetapi bobotnya sedang karena efluen dari IPAL telah mengalami pengenceran air sungai sehingga konsentrasi pencemar juga menurun.

g. Fauna darat

Prakiraan resiko terhadap fauna darat berasal dari tumpukan sampah kemudian dimakan. Selain itu gangguan terhadap fauna darat juga dari adanya gas methan. Resiko yang mungkin timbul berupa terakumulasinya unsur-unsur berbahaya seperti logam berat pada hewan yang selalu makan tumpukan sampah.

h. Fauna air

Prakiraan resiko terhadap fauna air berasal dari limbah cair yang berasal dari kolam pengolahan ke sungai. Resiko yang mungkin timbul berupa berkurangnya fauna di dalam air serta bersifat negatif. Bobotnya sedang karena effluen dari pabrik tahu telah mengalami pengolahan sehingga konsentrasi pencemar juga kecil, namun demikian pada kondisi tertentu IPAL akan mengalami gangguan. 
i. Tingkat kesehatan masyarakat

Prakiraan resiko terhadap tingkat kesehatan masyarakat berasal dari buangan pengolahan limbah cair yang masuk ke dalam air permukaan/sungai, di mana masyarakat sekitar tinggal dan memanfaatkan sungai. Disamping itu masyarakat juga mengkonsumsi air tanah yang terkontaminasi lindi yang meresap melalui lapisan dasar TPA. Resiko yang mungkin timbul berupa munculnya penyakit kulit, perut, dan sebagainya serta bersifat negatif. Bobotnya adalah besar karena berkaitan secara langsung dengan kehipuan manusia.

j. Estetika lingkungan

Prakiraan resiko terhadap estetika lingkungan berasal dari limbah cair yang dari kolam pengolahan yang masuk ke dalam air permukaan/sungai, limbah padat yang ditumpuk dan timbulnya gas yang menimbulkan bau tidak enak. Resiko yang mungkin terjadi berupa penurunan estetika lingkungan dan bersifat negatif serta bobotnya besar.

\section{Analisis Resiko}

Analisis Resiko Lingkungan merupakan kegiatan memperkirakan kemungkinan munculnya suatu resiko dari suatu kegiatan dan menentukan dampak dari kegiatan/peristiwa tersebut. Dalam studi ini, analisis digunakan metode kualitatif dan metode semi kuantitatif (Idris, 2003).

a. Metode kualitatif

Seperti dijelaskan pada bagian metodologi, maka nilai peluang resiko pada kegiatan TPA Piyungan dapat ditentukan seperti pada Tabel 5, sedangkan besarnya resiko ditunjukkan pada Tabel 6. Sehingga nilai resiko yang akan terjadi pada TPA Piyungan dapat ditentukan, yaitu ditunjukkan pada Tabel 7.

Berdasarkan analisis dengan menggunakan metode kualitatif dan metode semi kuantitatif diketahui nilai resiko pada setiap bagian maupun nilai resiko total. Nilai resiko yang dianalisis dengan menggunakan metode kualitatif diketahui sebagai berikut: dari 10 komponen lingkungan penerima resiko terdapat 3 komponen yang mempunyai nilai resiko tinggi $(\mathrm{H})$ atau 30\% yaitu: Pencemaran udara, Pencemaran air tanah, dan Berkurangnya estetika lingkungan. Untuk nilai resiko menengah 5 atau 50\% komponen masing-masing: Perubahan tata guna lahan, Pencemaran air permukaan, Penurunan jumlah flora air (aquatik), Penurunan jumlah fauna air, dan Penurunan tingkat kesehatan masyarakat. Sedangkan yang mempunyai nilai resiko rendah 2 atau 20\% komponen yaitu: Penurunan jumlah flora darat (terestrial) dan Penurunan jumlah fauna darat. 
Tabel 5. Matrik Peluang Resiko TPA Piyungan

\begin{tabular}{|l|c|l|}
\hline \multicolumn{1}{|c|}{ Resiko } & $\begin{array}{c}\text { Level } \\
\text { Peluang }\end{array}$ & \multicolumn{1}{c|}{ Uraian } \\
\hline $\begin{array}{l}\text { Perubahan tata } \\
\text { guna lahan }\end{array}$ & E & $\begin{array}{l}\text { Masyarakat menjual lahan karena menurunnya kenyamanan lingkungan, peluang } \\
\text { tejadinya resiko ini adalah jarang }\end{array}$ \\
\hline Pencemaran udara & B & $\begin{array}{l}\text { Pencemaran udara dapat terjadi karena bau dari timbulan gas dari proses degradasi } \\
\text { sampah. Peluang terjadinya pencemaran udara adalah besar }\end{array}$ \\
\hline $\begin{array}{l}\text { Pencemaran air } \\
\text { tanah }\end{array}$ & B & $\begin{array}{l}\text { Pencemaran air tanah dari kolam pengolahan lindi. Disamping itu terjadinya } \\
\text { bocoran ataupun rembesan pada lapisan dasar TPA yang menyebabkan lindi } \\
\text { meresap ke dalam tanah. Olek karena itu peluang terjadinya pencemaran air tanah } \\
\text { besar }\end{array}$ \\
\hline $\begin{array}{l}\text { Pencemaran air } \\
\text { permukaan }\end{array}$ & B & $\begin{array}{l}\text { Pencemaran air permukaan berasal dari efluen IPAL lindi yang dibuang ke sungai } \\
\text { walaupun sudah melalui proses pengolahan, maka peluang terjadinya pencemaran } \\
\text { air permukaan besar }\end{array}$ \\
\hline $\begin{array}{l}\text { Penurunan jumlah } \\
\text { flora darat } \\
\text { (terestrial) }\end{array}$ & D & $\begin{array}{l}\text { Penurunan jumlah flora darat akibat bau yang berasal dari proses degradasi } \\
\text { sampah, kemungkinan terjadinya kecil }\end{array}$ \\
\hline $\begin{array}{l}\text { Penurunan jumlah } \\
\text { flora air (aquatik) }\end{array}$ & C & $\begin{array}{l}\text { Jumlah flora air dapat menurun akibat lindi yang masuk ke air permukaan, dengan } \\
\text { peluang terjadinya sedang }\end{array}$ \\
\hline $\begin{array}{l}\text { Penurunan jumlah } \\
\text { fauna darat }\end{array}$ & D & Penurunan jumlah fauna darat di sekitar sungai akibat lindi yang dibuang kecil. \\
\hline $\begin{array}{l}\text { Penurunan jumlah } \\
\text { fauna air }\end{array}$ & C & Penurunan jumlah fauna air di sekitar sungai akibat lindi yang dibuang sedang \\
\hline $\begin{array}{l}\text { Penurunan tingkat } \\
\text { kesehatan } \\
\text { masyarakat }\end{array}$ & C & $\begin{array}{l}\text { Tingkat kesehatan masyarakat menurun akibat pencemaran air sumur oleh } \\
\text { rembesan lindi, peluangnya sedang }\end{array}$ \\
\hline $\begin{array}{l}\text { Berkurangnya } \\
\text { estetika } \\
\text { lingkungan }\end{array}$ & C & $\begin{array}{l}\text { Pencemaran air permukaan, tumpukan sampah, dan bau yang tidak enak maka } \\
\text { akan mengurangi estetika lingkungan, dengan peluang sedang }\end{array}$ \\
\hline
\end{tabular}

Keterangan: $A$ = Pasti terjadi; $B$ = Kemungkinan besar; $C=$ Kemungkinan sedang; $D=$ Kemungkinan kecil; $E=$ Jarang

Tabel 6. Matrik Besaran Resiko TPA Piyungan

\begin{tabular}{|c|c|c|}
\hline Resiko & $\begin{array}{c}\text { Level } \\
\text { Besaran }\end{array}$ & Uraian \\
\hline $\begin{array}{l}\text { Perubahan tata } \\
\text { guna lahan }\end{array}$ & 2 & $\begin{array}{l}\text { Kecil karena lahan yang ada di Piyungan berdasarkan RTRW bukan sebagai } \\
\text { kawasan permukiman maupun industri }\end{array}$ \\
\hline Pencemaran udara & 4 & $\begin{array}{l}\text { Besar karena gas yang dihasilkan berbahaya dan jumlahnya besar sehingga menjadi } \\
\text { sulit diatasi }\end{array}$ \\
\hline $\begin{array}{l}\text { Pencemaran air } \\
\text { tanah }\end{array}$ & 4 & $\begin{array}{l}\text { Besar karena mempengaruhi manusia dan bila ini terjadi memerlukan prosedur } \\
\text { tertentu untuk penanganannya }\end{array}$ \\
\hline $\begin{array}{l}\text { Pencemaran air } \\
\text { permukaan }\end{array}$ & 3 & $\begin{array}{l}\text { Sedang karena mempengaruhi lingkungan dan manusia di sekitar sungai namun } \\
\text { dapat diawasi melalui kerjasama yang baik antara operator, pemerintah serta LSM }\end{array}$ \\
\hline $\begin{array}{l}\text { Penurunan jumlah } \\
\text { flora darat } \\
\text { (terestrial) }\end{array}$ & 2 & Kecil karena tidak terlalu dipengaruhi sampah \\
\hline $\begin{array}{l}\text { Penurunan jumlah } \\
\text { flora air (aquatik) }\end{array}$ & 3 & $\begin{array}{l}\text { Sedang karena mempengaruhi populasi ikan dan berdampak pada manusia dapat } \\
\text { diatasi dengan manajemen yang baik antara pihak-pihak terkait }\end{array}$ \\
\hline $\begin{array}{l}\text { Penurunan jumlah } \\
\text { fauna darat }\end{array}$ & 2 & Kecil karena tidak terlalu dipengaruhi sampah yang ada di TPA \\
\hline $\begin{array}{l}\text { Penurunan jumlah } \\
\text { fauna air }\end{array}$ & 3 & Sedang karena jumlah fauna yang menurun akibat adanya air yang tercemar lindi \\
\hline $\begin{array}{l}\text { Penurunan tingkat } \\
\text { kesehatan } \\
\text { masyarakat }\end{array}$ & 3 & Sedang karena berhubungan dengan kesehatan manusia \\
\hline $\begin{array}{l}\text { Berkurangnya } \\
\text { estetika } \\
\text { lingkungan }\end{array}$ & 4 & $\begin{array}{l}\text { Besar karena karena berhubungan dengan tingkat keindahan dan kenyamanan dan } \\
\text { sulit untuk diselesaikan dengan yang baik }\end{array}$ \\
\hline
\end{tabular}

Keterangan: 1 = Pengaruh tidak berarti; 2 = Pengaruh kecil; 3 = Pengaruhnya sedang; 4 = Pengaruhnya besar; 5 = Bencana 
Tabel 7. Matrik Nilai Resiko TPA Piyungan

\begin{tabular}{|l|c|c|c|}
\hline \multicolumn{1}{|c|}{ Resiko } & Peluang Resiko & Level Besaran & Nilai Resiko \\
\hline Perubahan tata guna lahan & E & $\mathbf{2}$ & $\mathrm{M}$ \\
\hline Pencemaran udara & B & $\mathbf{4}$ & H \\
\hline Pencemaran air tanah & B & $\mathbf{4}$ & $\mathrm{H}$ \\
\hline Pencemaran air permukaan & $\mathbf{B}$ & $\mathbf{3}$ & $\mathrm{M}$ \\
\hline Penurunan jumlah flora darat (terestrial) & $\mathbf{D}$ & $\mathbf{2}$ & $\mathrm{L}$ \\
\hline Penurunan jumlah flora air (aquatik) & $\mathbf{C}$ & $\mathbf{3}$ & $\mathrm{M}$ \\
\hline Penurunan jumlah fauna darat & $\mathbf{D}$ & $\mathbf{2}$ & $\mathrm{M}$ \\
\hline Penurunan jumlah fauna air & $\mathbf{C}$ & $\mathbf{3}$ & $\mathrm{M}$ \\
\hline Penurunan tingkat kesehatan masyarakat & $\mathbf{C}$ & $\mathbf{3}$ & $\mathrm{H}$ \\
\hline Berkurangnya estetika lingkungan & C & $\mathbf{4}$ & \\
\hline
\end{tabular}

Keterangan: H: Resiko tinggi; M: Resiko menengah; S: Resiko berarti; L: Resiko rendah

Tabel 8. Matrik Frekuensi Kejadian Resiko TPA Piyungan

\begin{tabular}{|l|c|l|}
\hline \multicolumn{1}{|c|}{ Resiko } & $\begin{array}{l}\text { Frekuensi } \\
\text { Kejadian }\end{array}$ & \multicolumn{1}{|c|}{ Uraian } \\
\hline $\begin{array}{l}\text { Perubahan tata guna } \\
\text { lahan }\end{array}$ & $\mathbf{2}$ & $\begin{array}{l}\text { Masyarakat menjual lahannya karena menurunnya kenyamanan lingkungan, } \\
\text { hal ini jarang terjadi }\end{array}$ \\
\hline Pencemaran udara & $\mathbf{4}$ & $\begin{array}{l}\text { Frekuensi kejadian pencemaran udara akibat timbulan yang timbul dari } \\
\text { tumpukan sampah dan proses pengolahan lindi adalah akan sering terjadi. }\end{array}$ \\
\hline Pencemaran air tanah & $\mathbf{4}$ & $\begin{array}{l}\text { Frekuensi pencemaran air tanah adalah besar sebagai akibat dari kolam } \\
\text { pengolahan lindi serta meresapnya lindi melalui lapisan dasar TPA }\end{array}$ \\
\hline $\begin{array}{l}\text { Pencemaran air } \\
\text { permukaan }\end{array}$ & $\mathbf{3}$ & $\begin{array}{l}\text { Kemungkinan terjadinya pencemaran air permukaan medium, akibat buangan } \\
\text { air dari kolam pengolahan limbah yang dibuang ke sungai. }\end{array}$ \\
\hline $\begin{array}{l}\text { Penurunan jumlah flora } \\
\text { darat (terestrial) }\end{array}$ & $\mathbf{2}$ & $\begin{array}{l}\text { Penurunan jumlah flora darat di sekitar sungai } \\
\text { akibat menyerap buangan air limbah yang } \\
\text { dibuang ke sungai frekuensinya kecil, }\end{array}$ \\
\hline $\begin{array}{l}\text { Penurunan jumlah flora } \\
\text { air (aquatik) }\end{array}$ & $\mathbf{3}$ & $\begin{array}{l}\text { Penurunan jumlah flora air akibat limbah yang masuk mempunyai frekuensi } \\
\text { medium. }\end{array}$ \\
\hline $\begin{array}{l}\text { Penurunan jumlah } \\
\text { fauna darat }\end{array}$ & $\mathbf{2}$ & $\begin{array}{l}\text { Penurunan jumlah fauna darat akibat tercemarnya lingkungan dan } \\
\text { berkurangnya makanan, mempunyai frekuensi kecil. }\end{array}$ \\
\hline $\begin{array}{l}\text { Penurunan jumlah } \\
\text { fauna air }\end{array}$ & $\mathbf{3}$ & $\begin{array}{l}\text { Jumlah fauna air yang menurun akibat pencemaran dari berkurangnya flora } \\
\text { air mempunyai frekuensi medium. }\end{array}$ \\
\hline $\begin{array}{l}\text { Penurunan tingkat } \\
\text { kesehatan masyarakat }\end{array}$ & $\mathbf{3}$ & $\begin{array}{l}\text { Penurunan tingkat kesehatan masyarakat akibat penggunaan air sumur untuk } \\
\text { mandi, cuci, dan memasak frekuensinya kecil. }\end{array}$ \\
\hline $\begin{array}{l}\text { Berkurangnya estetika } \\
\text { lingkungan }\end{array}$ & $\mathbf{4}$ & $\begin{array}{l}\text { Pencemaran air, bau tidak sedap dan tumpukan sampah } \\
\text { mengurangi estetika, frekuensinya besar. }\end{array}$ \\
\hline
\end{tabular}

Keterangan: 1 = ada kemungkinan tidak terjadi; 2 = kecil; 3 = medium; 4 = sering; 5 = sangat sering terjadi

Tabel 9. Matrik Senstifitas Kejadian Resiko TPA Piyungan

\begin{tabular}{|l|c|l|}
\hline \multicolumn{1}{|c|}{ Resiko } & $\begin{array}{c}\text { Sensitifitas } \\
\text { Kejadian }\end{array}$ & \multicolumn{1}{c|}{ Uraian } \\
\hline Perubahan tata guna lahan & $\mathbf{2}$ & Menjadi perhatian dari kelompok tertentu \\
\hline Pencemaran udara & $\mathbf{4}$ & Menjadi perhatian nasional \\
\hline Pencemaran air tanah & $\mathbf{3}$ & Menjadi perhatian regional lokal. \\
\hline Pencemaran air permukaan & $\mathbf{3}$ & Menjadi perhatian dari pemerintah lokal dan masyarakat lokal \\
\hline Penurunan jumlah flora darat (terestrial) & $\mathbf{2}$ & Menjadi perhatian dari kelompok tertentu. \\
\hline Penurunan jumlah flora air (aquatik) & $\mathbf{2}$ & Menjadi perhatian dari kelompok tertentu. \\
\hline Penurunan jumlah fauna darat & $\mathbf{2}$ & Menjadi perhatian dari kelompok tertentu. \\
\hline Penurunan jumlah fauna air & $\mathbf{3}$ & Menjadi perhatian masyarakat lokal. \\
\hline Penurunan tingkat kesehatan masyarakat & $\mathbf{3}$ & Menjadi perhatian masyarakat lokal. \\
\hline Berkurangnya estetika lingkungan & $\mathbf{3}$ & Tidak menjadi perhatian masyarakat lokal. \\
\hline
\end{tabular}

Keterangan: 5 = Menjadi internasional/dunia/media; 4 = Menjadi perhatian nasional; 3 = Menjadi perhatian regional/local;

2 = Menjadi perhatian kelompok; 1 = Tidak menjadi perhatian masyarakat 
Tabel 10. Matrik Nilai Resiko TPA Piyungan

\begin{tabular}{|c|c|c|c|c|}
\hline Resiko & $\begin{array}{l}\text { Frekuensi } \\
(F)\end{array}$ & $\begin{array}{l}\text { Pengaruh } \\
\text { (S1) }\end{array}$ & $\begin{array}{c}\text { Sensitifitas } \\
\text { (S2) }\end{array}$ & $\begin{array}{c}\text { Nilai Resiko } \\
\text { Fx }(S 1+S 2)\end{array}$ \\
\hline Perubahan tata guna lahan & 2 & 2 & 2 & 8 \\
\hline Pencemaran udara & 4 & 4 & 4 & 32 \\
\hline Pencemaran air tanah & 4 & 4 & 3 & 28 \\
\hline $\begin{array}{l}\text { Pencemaran air } \\
\text { permukaan }\end{array}$ & 3 & 3 & 3 & 18 \\
\hline Penurunan jumlah flora darat (terestrial) & 2 & 2 & 2 & 8 \\
\hline Penurunan jumlah flora air (aquatik) & 3 & 3 & 2 & 15 \\
\hline Penurunan jumlah fauna darat & 2 & 2 & 2 & 8 \\
\hline Penurunan jumlah fauna air & 3 & 3 & 3 & 18 \\
\hline Penurunan tingkat kesehatan masyarakat & 3 & 3 & 3 & 18 \\
\hline Berkurangnya estetika lingkungan & 4 & 4 & 3 & 28 \\
\hline Total resiko & & & & 181 \\
\hline
\end{tabular}

Keterangan:

$0-150=$ Resiko rendah, pengelolaan dengan prosedur yang rutin .

$151-300=$ Resiko sedang, memerlukan perhatian manajemen tingkat tinggi .

$301-450=$ Resiko tinggi, memerlukan penelitian dan manajemen terperinci

b. Metode semi kuantitatif

Dalam metode semi kuantitatif, maka frekuensi kejadian pada kegiatan TPA Piyungan dapat ditentukan seperti pada Tabel 8, besarnya pengaruh ditunjukkan pada Tabel 6 dan nilai sensitifitas ditunjukkan pada Tabel 9. Sehingga nilai resiko yang akan terjadi pada TPA Piyungan dapat ditentukan, yaitu ditunjukkan pada Tabel 10.

Berdasarkan analisis dengan menggunakan metode semi kuantitatif diketahui nilai resiko pada setiap bagian maupun nilai resiko total. Nilai resiko yang dianalisis pada setiap komponen diketahui sebagai berikut: Dari 10 komponen lingkungan penerima resiko terdapat 3 atau 30\% komponen yang mempunyai nilai resiko lebih dari 25 (tinggi) yaitu: Pencemaran udara, Pencemaran air tanah, dan Berkurangnya estetika lingkungan. Untuk nilai resiko antara 15 sd 25 (sedang) terdapat 4 atau 40\% komponen masing-masing: Pencemaran air permukaan, Penurunan jumlah flora air (aquatik), Penurunan jumlah fauna air, dan Penurunan tingkat kesehatan masyarakat. Sedangkan yang mempunyai nilai resiko kurang dari 15 (rendah) atau 30\% komponen yaitu: Penggunaan tata guna lahan, Penurunan jumlah flora darat (terestrial) dan Penurunan jumlah fauna darat. Adapun secara total nilai resikonya adalah sedang dengan nilai 181.

\section{Kesimpulan dan Saran}

\section{Kesimpulan}

Berdasarkan hasil analisis kualitatif dan analisis semi kuantitatif beberapa komponen resiko dari adanya TPA Piyungan Yogyakarta dapat disimpulkan sebagai berikut: 
a. Komponen yang mempunyai nilai resiko tinggi adalah: pencemaran udara, pencemaran air tanah, dan berkurangnya estetika lingkungan pencemaran air permukaan yang disebabkan adanya timbulan gas, aliran lindi, rembesan lindi pada tanah serta bau yang tidak enak.

b. Komponen dengan nilai resiko sedang bedasarkan metode kualitatif adalah pencemaran udara, pencemaran air tanah, dan berkurangnya estetika lingkungan sedangkan didasarkan metode semi kuantitatif adalah penggunaan tata guna lahan, pencemaran udara, pencemaran air tanah, dan berkurangnya estetika lingkungan.

c. Komponen dengan nilai resiko rendah bedasarkan metode kualitatif adalah penurunan jumlah flora darat (terestrial) dan penurunan jumlah fauna darat sedangkan didasarkan metode semi kuantitatif adalah penggunaan tata guna lahan, penurunan jumlah flora darat (terestrial) dan penurunan jumlah fauna darat.

\section{Saran}

1. Untuk memperoleh hasil yang lebih akurat dan tingkat resiko yang representatif perlu diadakan studi yang lebih komprehensif utamanya dalam proses indentifikasi dan pengumpulan rona lingkungan yang lebih lengkap.

2. Berkaitan dengan komponen resiko tinggi, maka manajemen TPA Piyungan perlu melakukan penelitian dan menyusun program pengelolaan secara terperinci yaitu proses pengolahan lindi, rembesan lindi melalui lapisan dasar TPA dan penanganan timbulan gas.

\section{Daftar Pustaka}

Alia Damayanti; Joni Hermana; dan Ali Masduqi. (2004). Analisis Resiko Lingkungan dari pengolahan Limbah Pabrik Tahu Dengan Kayu Apu, Jurnal Purifikasi, Vol.5, No.4, Oktober 2004: 151-156, Jurusan Teknik Lingkungan FTSP-ITS.

Golder Associates (NZ) Ltd. (2002). Risk Assessment for Small Closed Landfills, Waste Mangement Institute New Zeland.

Glenn W. Suter II; Rebecca A. Efroymson; Bradley E. Sample; Daniel S. Jones. (2000). Ecological Risk Assessment for Contaminated Sites, LEWIS PUBLISHERS, Washington, D.C

Idris, Y.Z. (2003). Analisa Resiko Limbah Industri Tapioka di Sungai Tulang Bawang. Program Pascasarjana. Program Studi Magister Teknik Lingkungan ITS, Surabaya.

Razif, M. (2002). Analisis Resiko Lingkungan. Jurusan Teknik Lingkungan, Fakultas Teknik Sipil dan Perencanaan ITS, Surabaya.

Susan Dempsey, MS. (2007). Environmental Risk Assessement, Departement of Health \& Human services, Centennial Mall South, Nebraska 68509.

SEPA. (2002). The Geological Barrier, Mineral Layer and the Leachate Sealing and Drainage System, Framework for Risk Assessment for Landfill Sites.

U.S. EPA (Environmental Protection Agency). 1997. EPA's Composite Model for Leachate Migration with Transformation Products. EPACMTP: User's Guide. Office of Solid Waste, Washington, DC. 